\title{
Effect of Pre- Ovulatory Follicle Size on Pregnancy Rate in Murrah Buffaloes
}

\author{
Sushobhit Kr. Singh ${ }^{1 *}$, S. Mehrotra ${ }^{1}$, Pradeep Chandra ${ }^{1}$, M. K. Patra ${ }^{1}$, Brijesh Kumar ${ }^{1}$, \\ Harendra Kumar ${ }^{1}$, A. K. S. Tomar ${ }^{2}$ and Gyanendra Singh ${ }^{3}$ \\ ${ }^{1}$ Animal Reproduction Division, ${ }^{3}$ Division of Physiology and Climatology, ICAR-Indian \\ Veterinary Research Institute, Izatnagar- 243122, India \\ ${ }^{2}$ LPM Section, ICAR- IVRI, Izatnagar, 243122, India \\ *Corresponding author
}

\section{A B S T R A C T}

\begin{tabular}{|l|}
\hline Keyw or d s \\
Pre-ovulatory \\
follicle, Murrah, \\
Oestrus
\end{tabular}

The present study was conducted on oestrus Murrah buffaloes presented for artificial insemination (AI) at Cattle and Buffalo farm, Livestock Production and Management (LPM) section of the institute during August, 2019 to March, 2020. The buffaloes were scanned ultrasonographically to record size of the pre- ovulatory follicle (POF). The buffaloes were simultaneously inseminated by frozen thawed semen twice as per AM- PM schedule. Pregnancy diagnosis was performed thirty days post insemination by per- rectal ultrasonography (USG). Out of total 60 buffaloes, $60 \%$ had POF on their left ovary and $40 \%$ on right. POF size was significantly smaller $(11.37 \pm 0.39 \mathrm{~mm})$ in heifers which became pregnant in contrast to non- pregnant $(14.31 \pm 0.92 \mathrm{~mm})$, however it did not differ significantly in parous buffaloes. It was recorded that larger sized POF had lower pregnancy rate $(35.7 \%)$ in comparison to smaller $(50.00 \%)$ and medium $(50.00 \%)$ sized POF. In conclusion, pregnant heifers had smaller POF size than non pregnant and higher pregnancy rates were associated with smaller and medium sized POF, in comparison to large.

\section{Introduction}

In global scenario, buffalo population is increasing continuously, with 109.85 million buffalo population $\left(20^{\text {th }}\right.$ Livestock census, GOI, 2019) in India alone. Rightly termed as "The Black Gold" (Acharya and Bhat, 1988), they have played a pivotal role in achieving red and white revolution (Raj et al., 2018), but because of their poor breeding capabilities, they are not credited their due importance (Agarwal and Tomar, 2003), the major limitation being lower pregnancy rate after AI (Thirunavukkarasu and Kathiravan, 2009). One of the important aspects of successful AI is the correct time of insemination in synchrony with time of ovulation. It is reported that POF size affects oestrogen levels, oestrus behavior, and subsequent corpus luteum size and pregnancy rate. There are reports indicating positive correlations between pregnancy rate and size of POF at the time of AI in cattle (Nosier, 2003; Perry et al., 2007) and buffaloes 
(Pandey et al., 2011, Raj et al., 2018). In cattle heifers, greater follicle size yielded better pregnancy rates. Interestingly, ovulatory follicle size did not affect pregnancy establishment when cows exhibited oestrus and underwent spontaneous ovulation unlike during synchronized oestrus (Perry et al., 2005). However, larger follicles are found to be linked with reduced fertility as there is aging of the oocyte in cattle (Mihm et al., 1996 \& Revah and Butler, 1996). The available literature indicates discrepancy in information regarding relationship between POF size and pregnancy. Hence, the present study was aimed to determine the difference between POF size in heifer and parous Murrah buffaloes and its effect on pregnancy rates.

\section{Materials and Methods}

The present study was conducted at Cattle and Buffalo farm, LPM section, ICAR- IVRI; during August, 2019 to March, 2020. Oestrus detection was based on teaser bull parading twice daily (morning - evening) and visual observation of oestrus signs. A total of 60 Murrah buffaloes detected in standing oestrus, free from any apparent reproductive pathology were included in the study. Oestrus was further confirmed by per- rectal examination.

\section{Ultrasonography}

B-Mode ultrasonographic scanning $\left(\mathrm{EXAGO}^{\mathrm{TN}}, \mathrm{ECM}\right.$, France) using linear probe (7.5 MHz) was performed to determine POF size in either of the ovary. The size of the follicle was determined as, average of measurement of the two perpendicular largest diameters calculated using inbuilt scale. POF size at the time of AI (standing oestrus) were categorized as small (10 to $12 \mathrm{~mm}$ ), medium $(>12$ to $<14 \mathrm{~mm})$ and large $(>14 \mathrm{~mm})$ according to Pandey et al., (2011).

\section{Artificial insemination and pregnancy diagnosis}

AI was done twice as per AM - PM schedule with good quality frozen thawed semen supplied under AICRP on Buffalo improvement. Pregnancy diagnosis was done after day 30 post insemination by B- mode USG.

\section{Statistical analysis}

It was carried out by independent $t$-test used to compare the POF size between different groups for comparison. Effect of POF size on pregnancy rate was determined by $C h i$-square analysis. All the data was statistically analyzed using the IBM- SPSS 20.0 system for windows.

\section{Results and Discussion}

On the basis of per- rectal USG it was found that $60 \%(36 / 60)$ of the total buffaloes exhibited POF on their left ovary and $40 \%$ (24/60) had on right ovary. The mean size of POF on left ovary $(13.25 \pm 0.27 \mathrm{~mm})$ did not differ with that of right $(13.12 \pm 0.35 \mathrm{~mm})$. Similarly, the pregnancy rate also differed non- significantly in former $(50.00 \%)$ when compared to later (41.66\%).

The buffaloes when further grouped based on their parity, the POF size was found to be non- significantly smaller $(12.97 \pm 0.27 \mathrm{~mm})$ in heifers than parous $(13.25 \pm 0.22 \mathrm{~mm})$, with similar pregnancy rates among the groups (45.45\% vs. $46.94 \%)$.

Retrospectively, animals were grouped based on their pregnancy status (Table 1), it was found that POF size in pregnant buffaloes was smaller $(11.37 \pm 0.39$ and $13.18 \pm 0.24$, heifer and parous respectively) when compared to non- pregnant buffaloes (14.31 \pm 0.92 and $13.31 \pm 0.35$, respectively). Though, the POF 
size was significantly $(p<0.05)$ larger in nonpregnant heifers $(14.31 \pm 0.92)$ as compared to pregnant heifers $(11.37 \pm 0.39)$.

Buffaloes were also grouped based on their POF size as small (10 to $12 \mathrm{~mm}$ ), medium
$(>12$ to $<14 \mathrm{~mm})$, and large $(>14 \mathrm{~mm})$ groups; and it was found that the pregnancy rate was poor in large $(35.71 \%)$ sized POF group in comparison to small $(50.00 \%)$ and medium $(50.00 \%)$ sized POF (Table 2).

Table.1 POF size (Mean \pm SEM) in pregnant and non- pregnant buffaloes

\begin{tabular}{|l|c|c|c|}
\hline Parity & Pregnancy Status & POF Size $(\mathbf{m m})$ & Range $\mathbf{( m m})$ \\
\hline \multirow{2}{*}{ Heifer } & Pregnant & $11.37 \pm 0.39^{\mathrm{a}}$ & $10.15-12.55$ \\
\cline { 2 - 4 } & Non- Pregnant & $14.31 \pm 0.92^{\mathrm{b}}$ & $10.70-17.00$ \\
\hline \multirow{2}{*}{ Parous } & Pregnant & $13.18 \pm 0.24^{\mathrm{a}}$ & $11.30-15.65$ \\
\cline { 2 - 4 } & Non- Pregnant & $13.31 \pm 0.35^{\mathrm{a}}$ & $10.00-17.15$ \\
\hline
\end{tabular}

Values with different superscripts within column differ significantly $(p<0.05)$

Table.2 POF size (Mean \pm SEM) and pregnancy rate in small, medium, and large POF grouped buffaloes

\begin{tabular}{|c|c|c|}
\hline Category & POF Size (mm) & PR (\%) \\
\hline Small (10 to 12) & $11.41 \pm 0.17^{\mathrm{a}}$ & $50.00^{\mathrm{a}}(08 / 16)$ \\
\hline Medium (>12 to $<\mathbf{1 4})$ & $13.04 \pm 0.09^{\mathrm{b}}$ & $50.00^{\mathrm{a}}(15 / 30)$ \\
\hline Large $(>\mathbf{1 4})$ & $15.58 \pm 0.26^{\mathrm{c}}$ & $35.71^{\mathrm{a}}(05 / 14)$ \\
\hline
\end{tabular}

Values with different superscripts differ significantly $(p<0.05)$.

In the present study, it was found that $60 \%$ of total buffaloes had POF on their left ovary and only $40 \%$ on the right ovary. The size of POF on left ovary $(13.25 \pm 0.27 \mathrm{~mm})$ was slightly larger than right $(13.12 \pm 0.35 \mathrm{~mm})$. Similar findings were also reported, in Iraqi buffaloes wherein POF size on the right and left ovaries were $10.78 \mathrm{~mm}$ and $11.24 \mathrm{~mm}$, respectively (Azawi et al., 2009) without significant difference.

When POF size was grouped based on the parity, the POF size was found to be nonsignificantly smaller $(12.97 \pm 0.27 \mathrm{~mm})$ in heifers than parous $(13.25 \pm 0.22 \mathrm{~mm})$ buffaloes in present study which is in agreement with Raj et al., (2018) who also reported larger follicle size in pluriparous buffaloes $(15.3 \mathrm{~mm})$ than the primiparous (15.07 mm). Tenhagen et al., (2003) sighted that follicle size is affected by parity, with primiparous cattle producing smaller follicles than pluriparous ones. Pluriparous animals are known to produce milk; this increasing milk production leads to more feed intake and steroid metabolism that could have potential effects on the increasing POF size in multiparous cows (Tenhagen et al., 2003, Wiltbank et al., 2006). The pregnancy rates were almost similar in both the heifer and parous groups $(45.45 \%$ vs. $46.94 \%)$.

Retrospectively, when animals were grouped based on their pregnancy status, it was found that overall POF size in pregnant heifer and parous buffaloes was smaller (11.37 \pm 0.39 and $13.18 \pm 0.24 \mathrm{~mm}$ ) when compared to nonpregnant $(14.31 \pm 0.92$ and $13.31 \pm 0.35 \mathrm{~mm})$. The acceptable pregnancy rates $(50.00 \%)$ were recorded in small and medium sized POF groups, unlike poorer with large sized POF group $(35.71 \%)$. POF size $>10.7$ and < 
$15.7 \mathrm{~mm}$ has been shown yielding maximum pregnancy rates in cows (Perry et al., 2007) which is in concurrence with the present study. It has been documented that with increasing POF size, conception rate decreases in cows (Lynch et al., 2010, Vasconcelos et al., 1999). On the contrary, studies have reported that larger POF contributed to higher pregnancy rates (Raj et al., 2018 and Pandey et al., 2011).

The difference in the findings could be due to species and breed variation, method of oestrus detection, nature of oestrus (spontaneous or induced) and method of breeding (natural or AI).

\section{Acknowledgement}

We thankfully acknowledge the support provided by the Director, Indian Veterinary Research Institute (IVRI) for the necessary facilities provided.

\section{References}

Acharya, R. M. and Bhat, P. N. 1988. Status paper on buffalo production and health. In: Proceedings of II $^{\text {nd }}$ world buffalo congress held in India, December 12-16, 1988 1: 75-101.

Agarwal, S.K. and Tomar, O.S. 2003. Reproductive Technologies in Buffalo. Indian Vet. Res. Inst., Izatnagar, India.

Azawi, O.I., Ali, A.J. and Noaman, U.T., 2009. A study on the ovarian follicular dynamic in Iraqi Northern Buffaloes. Tropical animal health and production, 41(1): 79-83.

GOI. 2019. Twentieth Livestock Census, Department of Animal Husbandry Dairying and Fisheries, Ministry of Agriculture, Government of India, New Delhi, India. 120.

Lynch, C.O., Kenny, D.A., Childs, S. and Diskin, M.G., 2010. The relationship between periovulatory endocrine and follicular activity on corpus luteum size, function, and subsequent embryo survival. Theriogenology, 73(2):190198.

Mihm, M., Diskin, M.G. and Roche, J.F., 1996. Regulation of follicle wave growth in cattle. Reproduction in Domestic Animals (Germany).

Noseir, W.M., 2003. Ovarian follicular activity and hormonal profile during estrous cycle in cows: the development of 2 versus 3 waves. Reproductive Biology and Endocrinology, 1(1):1-6.

Pandey, A.K., Dhaliwal, G.S., Ghuman, S.P.S. and Agarwal, S.K., 2011. Impact of pre-ovulatory follicle diameter on plasma estradiol, subsequent luteal profiles and conception rate in buffalo (Bubalus bubalis). Animal Reproduction Science, 123(3-4):169-174.

Perry, G.A., Smith, M.F., Lucy, M.C., Green, J.A., Parks, T.E., MacNeil, M.D., Roberts, A.J. and Geary, T.W., 2005. Relationship between follicle size at insemination and pregnancy success. Proceedings of the National Academy of Sciences, 102(14): 5268-5273.

Perry, G.A., Smith, M.F., Roberts, A.J., MacNeil, M.D. and Geary, T.W., 2007. Relationship between size of the ovulatory follicle and pregnancy success in beef heifers. Journal of animal science, 85(3): 684-689.

Raj, M.P., Naidu, G.V., Srinivas, M., Raghunath, M. and Rao, K.A., 2018. Effect of preovulatory follicle on fertility in Graded Murrah buffaloes (Bubalus bubalis). Indian Journal of Animal Research, 52(6): 834-838.

Revah, I. and Butler, W.R., 1996. Prolonged dominance of follicles and reduced viability of bovine oocytes. Reproduction, 106(1): 39-47.

Tenhagen, B.A., Wittke, M., Drillich, M. and Heuwieser, W., 2003. Timing of 
ovulation and conception rate in primiparous and multiparous cows after synchronization of ovulation with GnRH and PGF2 $\alpha$. Reproduction in domestic animals, 38(6):451-454.

Thirunavukkarasu, M. and Kathiravan, G., 2009. Factors affecting conception rates in artificially inseminated bovines. Indian Journal of Animal Sciences, 79(9): 871.

Vasconcelos, J.L.M., Silcox, R.W., Rosa, G.J.M., Pursley, J.R. and Wiltbank, M.C., 1999. Synchronization rate, size of the ovulatory follicle, and pregnancy rate after synchronization of ovulation beginning on different days of the estrous cycle in lactating dairy cows. Theriogenology, 52(6): 1067-1078.

Wiltbank, M., Lopez, H., Sartori, R., Sangsritavong, S. and Gümen, A., 2006. Changes in reproductive physiology of lactating dairy cows due to elevated steroid metabolism. Theriogenology, 65(1):17-29.

\section{How to cite this article:}

Sushobhit Kr. Singh, S. Mehrotra, Pradeep Chandra, M. K. Patra, Brijesh Kumar, Harendra Kumar, A. K. S. Tomar and Gyanendra Singh. 2020. Effect of Pre- Ovulatory Follicle Size on Pregnancy Rate in Murrah Buffaloes. Int.J.Curr.Microbiol.App.Sci. 9(08): 2968-2972. doi: https://doi.org/10.20546/ijcmas.2020.908.333 